\title{
Educação como instrumento de luta: A elevação do senso comum em Gramsci
}

\author{
Education as an instrument of struggle: The elevation of common sense in Gramsci.
}

Maria Dolores Campos Rebollar ${ }^{\dagger *}$

Comocitaresseartigo. Rebollar, M.D.C. Educação como instrumento de luta: A elevação do senso comum em Gramsci. Revista Mosaico. 2017 Jul./Dez.; 08 (2): 23-29..

Nota de Editora

Os artigos publicados na Revista Mosaico são de responsabilidade de seus autores. As informações neles contidas, bem como as opiniões emitidas, não representam pontos de vista da Universidade Severino Sombra ou de suas Revistas.

\begin{abstract}
Resumo
Este artigo apresenta algumas reflexões sobre a Educação desde uma perspectiva transformadora reconhecendo que vivemos num mundo dividido e em luta que gera imensas desigualdades. Por conseguinte, a Educação não pode ser entendida apenas como um processo para adquirir habilidades técnicas e/ou reproduzir as práticas sociais, culturais, filosóficas vigentes, mas, principalmente, um processo que vise transformá-las. Para isso, a mudança de um senso comum, que reproduz relações de dominação e subalternidade se faz necessária a partir do fortalecimento do senso crítico, da elevação deste senso comum para uma consciência filosófica, para a autoconsciência. A Educação, desde essa perspectiva, tem uma relação direta com a filosofiae a política. Ajuda-nos na reflexão algumas categorias de Antônio Gramsci.

Palavras-Chave: Educação.Senso comum; Hegemonia; Filosofia da Práxis.
\end{abstract}

\begin{abstract}
This article presents some reflections on an Education from a transformative perspective recognizing that we live in a divided and struggling world that generates immense inequalities. Therefore, Education can not be understood only as a process to acquire technical skills and / or to reproduce as current social, cultural, philosophical practices, but mainly, a process around transforming them. Therefore, a change of a common sense that reproduces relations of domination and subalternityis made from a strengthening of the critical sense, from the elevation of this common sense to a philosophical conscience, to a self-consciousness. Education, from this perspective, has a direct relationship with a philosophy and a policy. Some categories of Antonio Gramsci help us in the reflection.

Keywords: Education. Common sense.Hegemony.Philosophy of Praxis.
\end{abstract}

\section{Introdução}

"Considerando-se que 'toda relação de hegemonia é necessariamente uma relação pedagógica', cabe entender a educação como um instrumento de luta". (Saviani)

\section{Um mundo em luta}

Marx e Engels iniciavam o Manifesto do Partido Comunista afirmando que "a história de todas as sociedades até agora tem sido a história das lutas de classes", ou seja, a contraposição entre escravos e homens livres, feudais e vassalos, patrícios e plebeus,opressores e oprimidos. Reconheciam, portanto, as permanentes relações de opressão e de lutas por emancipação que movem a história humana.
Tais relações de opressão foram se modificando, mas não deixaram de existir. Exemplo claro é o que aconteceu com o surgimento do capitalismo industrial, quando despontaram duas grandes classes sociais: a burguesia (detentora dos meios de produção) e o proletariado (detentor da força produtiva). "A moderna sociedade burguesa, que surgiu do declínio da sociedade feudal, não aboliu as contradições de classe. Ela apenas colocou novas classes, novas condições de opressão e novas formas de luta no lugar das antigas" (Marx; Engels, 2008).

As relações de dominação e exploração ganharam amplitude e se recriaram nos processos de colonização, como no caso do Brasil, conformando uma reprodução capitalista com diversos padrões de dominação, interna e externa. Florestan Fernandes (1974) analisou: o

Afiliação dos autores: † Doutoranda no programa de Pós-graduação em educação da Universidade Federal Fluminense no Rio de Janeiro, na linha de Filosofia, Estética e Sociedade. A autora faz parte da Internacional Gramsci Society do Brasil (IGS/Brasil).

*lolacamposr@gmail.com 
colonialismo e o controle do comércio pelas nações europeias; o neocolonialismo surgido após a revolução industrial na Europa; a expansão de grandes empresas corporativas no continente, que se apossaram, por meio de mecanismos financeiros, pressão ou corrupção, do espaço ocupado anteriormente pelas empresas nativas; e a hegemonia econômica dos Estados Unidos no continente. O autor constata na década de 1970 que

Quando uma forma determinada de organização da economia capitalista e da sociedade era absorvida, isso ocorria em consequência de uma mudança de natureza do capitalismo na Europa e nos Estados Unidos, e novos padrões de dominação externa emergiam inexoravelmente. Por outro lado, uma organização aristocrática, oligárquica ou plutocrática da sociedade sempre concentrou extremamente a riqueza, o prestígio social e o poder em alguns estratos privilegiados. Em consequência, a institucionalização política do poder era realizada com a exclusão permanente do povo e o sacrifício consciente de um estilo democrático de vida. A integração nacional, como fonte de transformações revolucionárias e de desenvolvimento econômico, sócio cultural e político, tornou-se impossível. (FERNANDES, 1975, p.11-12)

Florestan Fernandez pensa que a dominação capitalista no Brasil não é consequência apenas da dominação externa, pois exerce um importante papel de articulação das burguesias nacionais com as burguesias hegemônicas dos países centrais (CARDOSO, 2005). As relações de exploração e dominação se estabelecem e se recriam internamente no país. Um dilema brasileiro apontado por Florestan é a resistência das elites a qualquer mudança social.O Brasil, herdeiro de um sistema escravocrata e senhorial, dependente da economia mundial e com uma burguesia que sempre teve a escola, a família, a igreja e o Estado como instituições chave para disseminar suas ideias, enfrentou e enfrenta o desafio permanente de ajudar a incorporar nos indivíduos e grupos subalternos, a possibilidade real de uma nova ordem social.

Atualmente, assistimos a complexificacão tanto nas formas de expansão e dominação exploratória do capital, financeirização, quanto nas formas organizativas e de resistência de grupos subalternos: Quilombolas, Movimento indígena, Atingidos por Barragens, Movimento Negro, Sem Terra, Sem Teto, Feministas. Nosso ponto de partida é, portanto, o reconhecimento desta permanente tensão e disputa histórica, a partir das relações de dominação de umas classes sociais ${ }^{1}$ para com outras, nacional e internacionalmente, que não parecem ter perdido vigência, muito pelo contrário. A tentativa de negar esta realidade dividida e em confronto com argumentos conciliatórios de classe tem sido feita a partir dos Estados de bem-estar, defendidos pela social democracia na Europa, cujo centro foi a ampliação do conceito de cidadania, a partir da ideia que os indivíduos são dotados de direitos sociais como educação, saúde, seguridade social e lazer. Entretanto, esta tentativa deve fracassar diante da atual crise capitalista, que vem colocando em risco o universo da igualdade de direitos dos trabalhadores, exacerbando a concentração de riqueza e exploração sem limite do ser humano e dos recursos naturais a nível global.

Interessa-nos aqui refletir, a partir do pensamento gramsciano, alguns dos mecanismos que fortalecem estas relações de dominação e conformismo passivo das classes dominadas. Entendendo com Gramsci que a hegemonia de uma proposta de sociedade, não se consegue só pela coerção, mas, principalmente, pela "obtenção da dominação cultural - isto é, sua capacidade de difundir por toda a sociedade suas filosofias, valores, gostos" (Buttigieg, 2003, p. 45), portanto, não se pode tratar o tema da educação sem reconhecer sua intrínseca relação com a filosofia e a política ${ }^{2}$.

Assim sendo, veremos a importância de pensar a educação desde uma perspectiva revolucionária, ou seja, que busca transformar as relações de dominação,como um conjunto de processos que teriam a capacidade de transformar ideias e promover conscientização, ou seja, "dar-se conta de ser subjugados e organizarse politicamente para se libertar" (Semeraro, 2009). Falamos da educação, neste mundo em luta, como operações de hegemonia que permeiam as formas de produção e reprodução econômica, política e cultural, apoiada em uma determinada "concepção de mundo" e obedecendo a um determinado projeto político, de sociedade.

\section{Senso comum}

Segundo Gramsci, o senso comum dos subalternos incorpora ideias e crenças de forma desagregada, acrítica, mecânica, desarticulada, mas ligada à vida prática, ainda que de forma incoerente. Contudo, o senso comum é um produto histórico dinâmico.

\footnotetext{
Cada estrato social posee su "sentido común" que en el fondo es la concepción de la vida y la moral más difundida. Cada corriente filosófica deja una sedimentación de "sentido común": es este el documento de su realidad histórica. El sentido común no es alzo rígido e inmóvil sino que se transforma continuamente enriqueciéndose con nociones científicas $y$ opiniones filosóficas introducidas en las costumbres.(GRAMSCI, 1981, p. 140)
}

O senso comum, que vai se transformando no devir histórico, é um conhecimento social que organiza as relações intersubjetivas e do cotidiano, sem que estas relações sejam questionadas por um período de tempo, produzindo certeza, reproduzindo a ordem social e, também, a legitimando (Tapia, 2007).

El sentido común también es una normativa que ordena el sentido de los hechos sociales. En este sentido, el sentido común es un compuesto de memoria y valoración. El sentido 
común contiene un tipo de memoria histórica y un modo de producir memoria histórica, es decir, de ordenar los hechos sociales e históricos de acuerdo a una estructura ideológicamente armada en el proceso de constitución de una cultura política como hegemónica.(TAPIA, 2007, p. 89).

É frequente descobrir no senso comum de grupos subalternos ideias e crenças que nutrem as relações de dominação e levam à reprodução das mesmas, à imobilidade e ao conformismo. Traços de uma forma de ler e incorporar o mundo dicotômica e fragmentariamente: ricos e pobres, bons e ruins, inteligentes e ignorantes, intelectuais e povo, quem pensa e quem faz. Além disso, percebe-se uma mistura desordenada dos tempos históricos, simplificando a realidade complexa e limitando a tomada de consciência para com as possibilidades alternativas, que se apresentam e coexistem nessa mesma realidade. Assim sendo, a educação pode ser encarada como processos de reprodução passiva ou se tornar estratégia fundamental para a elevação deste senso comum, ou seja, para tornálo crítico e para a incorporação de uma consciência que nos motive a ser protagonistas da história. Gramsci se perguntava início do século XX:

É preferível "pensar" sem disto ter consciência crítica, de uma maneira desagregada e ocasional, isto e, "participar" de uma concepção do mundo "imposta" mecanicamente pelo ambiente exterior, ou seja, por um dos muitos grupos sociais nos quais todos estão automaticamente envolvidos desde sua entrada no mundo consciente [...] ou é preferível elaborar a própria concepção do mundo de uma maneira consciente e crítica e, portanto, em ligação com este trabalho do próprio cérebro, escolher a própria esfera de atividade, participar ativamente na produção da história do mundo, ser o guia de si mesmo e não mais aceitar do exterior, passiva e servilmente, a marca da própria personalidade? (GRAMSCI, 1999, Q11§12, p.93-94)

Nossa concepção de mundo nos faz pertencer a um determinado grupo cujos modos de pensar e agir são semelhantes. Sendo "homens-coletivos" (Gramsci, Q11), um dos desafios é superar as formas de entendimento que nos deixam resignados, em situações de subjugação cultural, política e econômica. "Para isso é necessária a consciência da própria historicidade, da fase de desenvolvimento por ela representada e do fato de que ela está em contradição com outras concepções ou com elementos de outras concepções". (Gramsci, 1999, Q11, §12, p.95). Porque a história é feita pelos homens em movimento, que buscam chegar a determinados fins que se colocaram, "a história é, precisamente, o resultado dessas numerosas vontades projetadas em direções diferentes e de sua múltipla influência sobre o mundo exterior". (Marx; Engels, 2005)

Saviani(2012) apoiadona perspectiva gramsciana, aborda a questão da necessária passagem do senso comum à consciência filosófica. O que isso significa?
É “passar de uma concepção fragmentaria, incoerente, desarticulada, implícita, degradada, mecânica, passiva e simplista a uma concepção unitária, coerente, articulada, explicíta, original, intencional, ativa e cultivada. (Saviani, 1996, p.1). Desta forma, olhamos para a educação como instrumento de luta, porque subverte o modus operandi, apontando dois momentos necessários: a crítica à concepção dominante, e a elevação do senso comum para superar a condição subalterna.

Criticar a própria concepção do mundo, portanto, significa
torná-la unitária e coerente e elevá-la até o ponto atingido
pelo pensamento mundial mais evoluído. Significa também,
portanto, criticar toda a filosofia até hoje existente, na
medida em que ela deixou estratificações consolidadas
na filosofia popular. O início da elaboração crítica e a
consciência daquilo que é realmente, isto é, um "conhece-te
a ti mesmo" como produto do processo histórico até hoje
desenvolvido, que deixou em ti uma infinidade de traços
acolhidos sem análise crítica. Deve-se fazer, inicialmente,
essa análise. (GRAMSCI, 1999, Q11, §12, p94)

O neoliberalismo, segundo Tapia (2007), produziu um senso comum que contém fortes elementos pessimistas, em relação à importância e efetividade das ações coletivas de resistência - nada é possível fora do capitalismo. "El sentido común neoliberal a su vez funciona como una matriz atomizadora o atomizante, produce la individualización de las relaciones y los hechos" (Tapia, 2007, p.90). Tapia reconhece, também, no caso da Bolívia, uma "reforma intelectual e moral" que conseguiu rearticular novos elementos dentro do senso comum hegemônico, como "la autovaloración, la creencia en las propias fuerzas y la conciencia del robo y la explotación que significan los procesos de privatización y control transnacional de las economías" (Tapia, 2007, p.101). Podemos nos perguntar como é possível que dentro da hegemonia neoliberal possa acontecer isto? Parte da resposta a esta questão pode ser encontrada em análises econômicas, políticas e sociais junto à existência de processos educativos no âmbito da organização e das lutas populares, que exploram as contradições do sistema capitalista e que foram desenvolvidas ao longo de algumas décadas com os grupos subalternos fortalecendo seu senso crítico e, promovendo o fortalecimento de níveis de autonomia e autoconsciência. Dito de outra forma, se potencializa o bom senso ${ }^{4}$ existente no senso comum, incorporado acriticamente pelos subalternos. Potencializa-se, também, a capacidade de resistência que co-existe nos grupos, junto à imposição de ideias e crenças que os querem subalternos.

\footnotetext{
Junto às concepções de mundo da condição subalterna, reduzidas ao senso comum, parece coexistir "uma tenaz resistência e oposição à cultura hegemônica, sobre os traços mais ou menos frágeis de autonomia com respeito à "concepção de mundo" da "classe hegemônica" que os coloniza cotidianamente. (LIGUORI, 2011, p.160)
} 
Afinal, o que nos interessa aqui evidenciar é como a resistência e a mudança em relação à hegemonia econômica, política, cultural do capitalismo é possível dentro de um universo de grandes diversidades culturais, pois a hegemonia não se mantém apenas pela coerção, mas também pelo consenso. Existe uma história ampla de processos educativos, culturais, econômicos de resistência à dominação, que ainda hoje persistem na prática e memória histórica dos subalternos, como elementos dentro do senso comum, que pode ser levado a um novo patamar filosófico e político.

A educação deve dar condições para realizar esta passagem da "filosofia dos subalternos" a uma filosofia coerente, que "liberta" de uma concepção de mundo que nutre a opressão, adquirindo a capacidade de disputar hegemonia.

$\mathrm{Na}$ filosofia, destacam-se notadamente as características de elaboração individual do pensamento; no senso comum, ao contrário, destacam-se as características difusas e dispersas de um pensamento genérico de uma certa época em um certo ambiente popular. Mas toda filosofia tende a se tornar senso comum de um ambiente, ainda que restrito (de todos os intelectuais). Trata-se, portanto, de elaborar uma filosofia que - tendo já uma difusão ou possibilidade de difusão, pois ligada a vida prática e implícita nela — se torne um senso comum renovado com a coerência e o vigor das filosofias individuais. E isto não pode ocorrer se não se sente, permanentemente, a exigência do contato cultural com os "simples". (GRAMSCI, 1999, Q11, §12, p.100)

A concepção de mundo atual para ser hegemônica logrou obter o consenso ${ }^{5}$ ativo e passivo dos grupos sociais, transformando-se em senso comum.É por isso que na estrutura social sustentada nos antagonismos de classes e exploração humana, "as relações entre senso comum e filosofia se travam na forma de luta hegemônica" (Saviani, 1996, p. 2).

Luta hegemônica significa precisamente: processo de desarticulação rearticulação, isto e, trata-se de desarticular dos interesses dominantes aqueles elementos que estão articulados em torno deles, mas não são inerentes a ideologia dominante e rearticulá-los em torno dos interesses populares, dando-lhes a consistência, a coesão e a coerência de uma concepção de mundo elaborada, vale dizer, de uma filosofia. (SAVIANI, 1996, p. 2).

\section{Filosofia da Práxis}

Se a filosofia, pensada de forma geral e abrangente, está ligada à história e a problemas que todos têm e não à atividade de apenas um indivíduo, então possui uma relação direta com o senso comum. O diferencial da Filosofia da Práxis é que se propõe a pensar o mundo ativamente desde o chão da realidade concreta e não de forma especulativa. Esta Filosofia busca reformar o senso comum, busca a transformação social, portanto, está ligada a um projeto político ${ }^{6}$. Assim sendo, "hegemonía y filosofía son dos momentos estrictamente conectados entre ellos. La realización de un sistema hegemónico es la realización de una filosofia, es su historia concreta, su vertiente politica"?.

A Filosofia da Práxis concebe, desde a prática, um novo mundo no qual sejam destruídas as relações que gerem subalternidade. Desta forma, quando se fala de reformar o "senso comum" se faz buscando uma reforma desde dentro, e não desde fora.

Deste modo, Gramsci fala de Filosofia da Práxis se contrapondo às Filosofias positivistas e idealistas, o que vai torná-la uma nova filosofia, original e independente, que rejeita as explicações metafísicas e mecanicistas do mundo.

Uma Filosofia da Práxis só pode apresentar-se, inicialmente, em atitude polêmica e crítica como superação da maneira de pensar precedente e do pensamento concreto existente (ou mundo cultural existente). E, portanto, antes de tudo, como crítica do "senso comum" (e isto após basear-se sobre o senso comum para demonstrar que "todos" são filósofos e que não se trata de introduzir ex novo uma ciência na vida individual de "todos", mas de inovar e tornar "critica" uma atividade já existente). (GRAMSCI, 1999, Q11, §12 p. 101)

A Filosofia da Práxis reconhece que todos os homens são filósofos e não separa a teoria da prática, o fazer do pensar, o homem da natureza, rompendo com a lógica dicotômica que os separa.

Por isso, a unidade dialética entre teoria e prática (práxis) não é uma mera característica técnica e profissional que se "aprende fazendo", mas é uma revolucionária concepção integral de ser humano, de sociedade e de mundo que carrega o princípio teórico-prático da hegemonia e visa a transformar "de cima a baixo" a economia, a política, a filosofia, a ciência, a cultura, a educação, as relações de poder e a construir personalidades livres e associadas, em condições de realizar a "grande política: a criação de novos Estados" (Q 13, §5, p. 1564) e de dirigir democrática e integralmente a sociedade. (SEMERARO, 2017, p.32)

A partir desta Filosofia se busca o progresso intelectual das massas, não só de pequenos grupos, visando uma "reforma intelectual e moral" que construa as condições para um novo tipo de sociedade. Deste modo, quando falamos em "práxis" estamos falando com uma visão dialética "que sintetiza, na forma de superação, os dois elementos contrários representados pela teoria e pela prática. Nesse sentido, a práxis pode ser definida como atividade humana prática fundamentada teoricamente." (Saviani, 2017). É, portanto, necessário passar da prática social à práxis social, fugindo de idealismos que dissolvam a prática na teoria, ou de pragmatismos que dissolvam a teoria na prática.

Para Gramsci, quem tem a função especializada de reformar o senso comum são os intelectuais, inseridos organicamente na sociedade como indivíduos, e também, como coletivos, como "partidos", pois "um 
partido poderá ter uma maior ou menor composição do grau mais alto ou do mais baixo, mas não é isto que importa; importa a função, que é diretiva e organizativa, isto é, educativa, isto é, intelectual."'(Gramsci, 2011, p.25-"). Gramsci amplia originalmente o conceito de intelectual desde seu pensamento inovador, pois para ele intelectuais são todos aqueles que exercem um trabalho de organização e conexão das massas. Ou seja, os intelectuais orgânicos são os que estabelecem nexos entre a filosofia e o senso comum, "hacen la mediación entre la creatividad de un pensamiento nuevo y larealidad prática, política, histórica. Ellos transmitenla visión de mundo adaptándola a lenguajes, lugares y contextos especificos." "Para a Filosofia da Práxis os intelectuais não poderiam estar distanciados do povo. Assim sendo, há unificação entre a "alta cultura" e a "cultura popular", entre os intelectuais e as massas e, isto, busca ser uma nova política. A proposta visa romper com as relações de subalternidade estabelecendo uma permanente relação pedagógica, que deve ser experimentada, impulsionada no âmbito do "partido" (entendido desde uma concepção ampla de organizações políticas e populares).

Gramsci combate permanentemente a fragmentação. Para ele não há mundos separados; o deles e o nosso. Há um poder articulado em relações de dominação e subalternidade, e uma cultura articulada filosófica e politicamente para a dominação e subalternidade. Entretanto, dentro de tudo existem, ao mesmo tempo, as possibilidades para a construção de novas alternativas que modifiquem o tipo de relações.

A questão que se coloca aqui, é como se trava essa luta que é filosófica, política, pedagógica, para a superação das relações de dominação? Passa pela conquista de certa "autonomia" dos grupos subalternos, associada necessariamente ao desenvolvimento da consciência crítica e autoconsciência, que se produz, através da organização nas lutas e resistências concretas no campo político, econômico, social, educacional. " $L a$ consciencia de ser parte de una determinada fuerza hegemónica (o sea, la consciencia política) es la primera fase de una ulterior y progresiva autoconsciencia, en la cual se unifican finalmente la teoría y la práctica". (Sacristán, 1978, p. 373)

A partir daqui a educação toma uma dimensão que não pode ser limitada a questões técnicas nem ficar reduzida apenas ao âmbito escolar. Não se trata mais de pensar uma educação que separa o técnico do político e do filosófico. Há que pensar a educação "integral”, adjetivo que está vinculado nos escritos de Gramsci ao conceito de práxis, autonomia, criação, revolução, nova civilização. (Semeraro, 2017)

A educação se constitui, pois, num instrumento de luta para estabelecer uma nova relação hegemônica que permita constituir um novo bloco histórico sob a direção da classe fundamental dominada da sociedade capitalista - o proletariado. A importância fundamental da educação na luta pela hegemonia reside na elevação cultural das massas. (SAVIANI, 2017, p. 15)

Aeducaçãoétarefaessencialnalutapor hegemonia, pois "o dominado carrega a lógica do dominante dentro dele" (Gadotti; Freire; Guimarães, 1989). Esse senso comum, fragmentado, incoerente, desarticulado, passivo deve ser superado para transformar-se numa concepção unitária, coerente articulada, ativa em prol de "outro mundo possível" 1 .O processo pedagógico deve saber explorar as contradições e a capacidade de criação dos subalternos, a partir da prática e do que é real.

O homem ativo de massa atua praticamente, mas não tem uma clara consciência teórica desta sua ação, a qual, não obstante, e um conhecimento do mundo na medida em que o transforma. Pode ocorrer, aliás que sua consciência teórica esteja historicamente em contradição com o seu agir. É quase possível dizer que ele tem duas consciências teóricas (ou uma consciência contraditória): uma implícita na sua ação, e que realmente o une a todos os seus colaboradores na transformação pratica da realidade; e outra, superficialmente explicita ou verbal, que ele herdou do passado e acolheu sem crítica. (GRAMSCI, Q11, §12, p. 103)

Freire (1986) reconhecia o caráter dinâmico da consciência crítica, que submete a realidade à análise, e a contrapunha à consciência ingênua,que termina atribuindo aos acontecimentos e suas causalidades um caráter estático, de algo já feito e estabelecido. A consciência filosófica da qual fala Saviani (1996), se constitui como luta hegemônica e expressão de hegemonia, buscando "obter o consenso das diferentes camadas que integram a sociedade" (Saviani, 1996). Passar do senso comum à consciência filosófica é colocar a educação numa perspectiva revolucionária (Saviani, 1996).

A educação, por conseguinte, deve ser integral e efetiva
quando busca levar à "elaboração nacional unitária de
uma consciência coletiva homogênea" (Q 24, $\$ 3,2267)$
e constrói "a vontade coletiva e a vontade política no
sentido moderno, a vontade como consciência operosa
da necessidade histórica". (Semeraro, 2017, p.30)

Nos dias atuais, em nível global, experimentamos a exacerbação competitiva, o aumento alarmante da precarização do trabalho, a ameaça de guerras nucleares, a mudança climática, a crescente destruição dos recursos naturais, o ressurgimento de ideologias fascistas e o progressivo isolamento gerado pelas tecnologias da comunicação. Em nível nacional, estamos vivendo um golpe de Estado, que objetiva desmontar as conquistas sociais das últimas décadas, promovendo a perseguição e atomização de lideranças política se grupos populares. Tal realidade, em nível global e nacional, nos expõe a um medo paralisante e a uma fragmentação social de graves consequências. Diante disto,há que batalhar a 
esperança, a capacidade de luta, que passa pela análise rigorosa e a busca de brechas alternativas, fazendo a leitura das oportunidades que esta profunda crise, também, carrega. Manter a dinâmica passiva de um senso comum adormecido, de uma consciência ingênua, fechada em si mesma, irreal, desagregada, ou como Marcuse (1973) apontava, uma consciência infeliz, que incorpora sem oposição o capitalismo tecnológico, não parece o melhor caminho para transformar a sociedade. A educação não pode ser reduzida a um campo isolado, formal e técnico. A educação, desde esta perspectiva revolucionária, em qualquer âmbito, seja escolar, universitário, social, político ou religioso, tem a tarefa impreterível de reorganizar e conectar nossos potenciais e práticas transformadoras, que coexistem e também fazem parte da construção da nossa história.

\section{Notas}

1. Os conceitos de "classe", "luta de classes" e "consciência de classe" são pontos de referência principal na teoria marxista. Marx explicava no 18 Brumário de Luis Bonaparte (parte VII): Na medida em que milhões de famílias vivem sob condições econômicas de existência que separam seu modo de vida, seus interesses e a sua cultura daqueles das outras classes e as colocam em oposição hostil a essas outras classes, elas formam uma classe. Na medida em que há apenas uma interconexão local entre esses camponeses, de pequenas propriedades, e a identidade de seus interesses não gera nenhuma comunidade, nenhum elo nacional e nenhuma organização política entre eles, tais pessoas formam uma classe. No entanto, atualmente existem diversos estudos $\mathrm{e}$ polêmicas em torno à categoria na emergência da complexidade da estrutura social. Não nos cabe aqui entrar no assunto, por isso, optamos por um uso abrangente e aberto da categoria de "classe /classes", com base nas múltiplas utilizações adjetivadas,que Gramsci fez do termo nos Cadernos do Cárcere (classe política, classe intelectual, classe burguesa, classe operária, classe subalterna, classe dominante, classe fundamental etc.).

2. Dermeval Saviani (2012) reconhecendo a intrínseca relação entre educação e política, elaborou 11 teses sobre educação e política preocupado com "o risco de se identificar educação com política, a prática pedagógica com a prática política, dissolvendo-se, em consequência, a especificidade do fenômeno educativo". Entre os argumentos que defende, declara ser característico da política "vencer", e como característica da educação "convencer", assim a educação se constituiria como espaço de relações entre não antagônicos e a política entre antagônicos: "A política na sociedade de classes é uma luta entre antagônicos que supõe 'divisão da sociedade em partes inconciliáveis'. Por isso a prática política é partidária, mas a educação sendo entre não antagônicos, supõe união e universalidade. Entretanto, nos identificamos com a crítica feita por Moacir Gadotti, Paulo Freire e Sérgio Guimarães (1989) para os quais: "Vencer, como característica do político passa pelo convencimento, que é pedagógico", assim como, a relação entre antagônicos e não antagônicos se dá também no âmbito pedagógico sendo possível um ato pedagógico na luta entre antagônicos.

3. Usamos a expressão 'concepção de mundo' a partir do uso que Gramsci faz, como um sentido amplo de ideologia, "para indicar o terreno conectivo sobre o qual surgem graus diversos de elaboração das capacidades do sujeito de interpretar a realidade" (Liguori, 2017, p.136) e, que "indica tanto a filosofia dos simples, o senso comum, quanto às concepções elaboradas, hegemônicas ou potencialmente hegemônicas" (Liguori, 2017, p.135).

4. Usamos o conceito de "bom senso" a partir do pensamento de Gramsci. No Q $11 \S 1$, quando analisa expressões da linguagem do povo em relação à ideia que expressam sobre o que seja filosofia. Na expressão popular "tomar as coisas com filosofia" Gramsci encontra um convite à resignação e paciência, mas, também, um convite à reflexão e tomada de consciência:"Este é o núcleo sadio do senso comum, que poderia precisamente ser chamado de bom senso e que merece ser desenvolto e transformado em algo unitário e coerente". Gramsci mostra nesse caso, o "bom senso" positivamente e com potencial para a construção de uma coerência filosófica.

5. Para Gramsci o consenso está diretamente ligado à questão de hegemonia precisamente porque hegemonia não se adquire apenas pela coerção. A expressão "consenso dos governados" nos Cadernos do Cárcere é frequente quando Gramsci analisa a organização de consenso por parte do Estado e dos organismos privados da sociedade civil. O consenso obtido é o que mostra a capacidade dirigente de uma classe. "O consenso é ativo quando os governados participam da vida do organismo estatal em cuja condução há governantes aceitos por aqueles. $\mathrm{O}$ consenso passivo quando os governados subscrevem com atos formalmente democráticos (sufrágio) a aceitação daqueles que os guiam e que, por isso, numa perspectiva de democracia formal, tendencialmente os dominam." (LA PORTA, 2017, p.143)

6. A Filosofia da Práxis se apoia nas Teses Ad Feuerbach que Marx elaborou. Podemos lembrar as mais significativas nesse sentido: "É na práxis que o homem deve demonstrar a verdade, isto é, a realidade e a força, o caráter terreno do seu pensamento" (tese II); "os filósofos se limitaram a interpretar o mundo de diferentes maneiras, mas o que importa é transformá-lo"(tese XI). 
7. Este texto é de Fábio Frosine, que impartiu um curso sobre Antonio Gramsci na UFF sobre Gramsci e os intelectuais, em 2015. Pode-se encontrar em: https://www. youtube.com $/$ watch? $=\mathrm{gVTKBD} 5 \mathrm{eM} I \mathrm{I}$

8. Fábio Frosine, no Seminário Antonio Gramsci: Filosofia e política. UFF, 2015. Pode-se encontrar em: https://www.youtube.com/watch? $\mathrm{v}=\mathrm{gVTKBD} 5 \mathrm{eMlI}$

9. Esta expressão foi cunhada pelos movimentos sociais que organizam desde 2001 o Fórum Social Mundial para se contrapor à hegemonia do "pensamento único" (não há vida fora do capitalismo), na tentativa de articular e dar visibilidade a "outras formas de estar/fazer o mundo" existentes e negadas pelo sistema capitalista.

\section{Bibliografia}

BUTTIGIEG, Joseph A. Educação e hegemonia In COUTINHO; TEIXEIRA (Orgs). Ler Gramsci, entender a realidade. Rio de Janeiro: Civilização Brasileira, 2003.

CARDOSO, Miriam Limoneiro. Sobre a Teorização do capitalismo dependente em Florestan Fernandes In FÁVERO, Osmar (Org). Democracia e educação em Florestan Fernandes. Niterói, RJ: Ed.UFF, 2005.

FERNANDES, Florestán. Capitalismo Dependente e Classes Sociais na América Latina.Rio de Janeiro:Zahar Editores, 1975.

FREIRE, Paulo. La educación como práctica de libertad. Madrid: Siglo XXI de España Editores, S. A. 1986.

GADOTTI, Moacir; FREIRE, Paulo; GUIMARAES, Sérgio. Pedagogia: Diálogo e conflito. São Paulo:Cortez Editora, 1989.

GRAMSCI, Antonio. Cadernos do cárcere. COUTINHO, Carlos Nelson (ORG) Vol.1 Rio de Janeiro:Civilização Brasileira, 1999.

Cadernos do cárcere. COUTINHO, Carlos Nelson (ORG) Vol.3 Rio de Janeiro: Civilização Brasileira, 2011.

Cuadernos de la cárcel. Traducción de Ana María Palos. Tomo 1. $2^{a}$ edición. Méjico: Coedición Ediciones era/Benemérita. Universidad Autônoma de Puebla, 1981.

LA PORTA, Lelio. Consenso. In LIGUORI, Guido; VOZA, Pasquale. Dicionário Gramsciano (1926-1937). 1ª Edição. São Paulo: Boitempo, 2017.

LIGUORI, Guido. Concepção do mundo. In: LIGUORI, Guido; VOZA, Pasquale. Dicionário Gramsciano (1926-1937). 1 $1^{\text {a }}$ Edição. São Paulo: Boitempo, 2017.

Movimentos Sociais e papel do partido no pensamento de Gramsci e Hoje. In SEMERARO, Giovanni; OLIVEIRA, M. M.; SILVA, Percival, LEITÃO, Sônia. (Orgs) Gramsci e os Movimentos Populares. Niterói: Ed. UFF, 2011.

MARX, Kark; ENGELS, Friedrich. Manifesto do Partido Comunista. São Paulo:Editora Expressão Popular, 2008.

A Ideologia Alemã. Feuerbach - A contraposição entre as cosmovisões Materialista e Idealista. São Paulo: Editora Martin Claret Ltda. 2005

MARCUSE, Herbert A ideologia da sociedade industrial. O Homem unidimensional. Rio de Janeiro: Zahar Editores, 1973.

SACRISTÁN, Manuel. Antonio Gramsci. Antologia. México: Siglo veintiuno editores. Editorial Melo, s.a. 1978

SAVIANI, Dermeval. Educação, práxis e emancipação humana. Revista Práxis e Hegemonia Popular, nº 2, p.4-19.Jun-2017.

Do senso comum à consciência filosófica. 11 Edição. São Paulo: Coleção Educação contemporânea, 1996.

Escola e Democracia. Campinas, SP: Autores Associados, 2012.

SEMERARO, Giovanni. Libertação e hegemonia. São Paulo: Idéias\& Letras, 2009

Práxis e formação humana: a concepção "integral” de Gramsci.

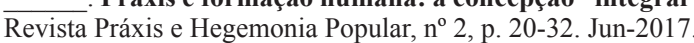

Pedagogia. In: LIGUORI, Guido; VOZA, Pasquale (orgs) Dicionário Gramsciano 1926-1937. São Paulo: Editora Boitempo, 2017.

TAPIA, Luis. Igualdad es cogobierno. La Paz:Asdi-Sarec y Plural editores, 2007. 